\title{
Penggunaan Tes Teichmann untuk Mengidentifikasi Bercak Darah yang Menempel pada Pakaian dengan Paparan Air Tawar, Tanah, dan Udara bebas
}

\author{
Adiarani Puspitaati ${ }^{*}$, Wening Prastowo**, Onggung MH Napitupulu***
}

\begin{abstract}
ABSTRAK
Darah adalah salah satu dari bukti fisik yang paling sering ditemukan pada tempat kejadian perkara. Darah lebih mudah dikenali karena berwarna merah tua, tetapi bisa berubah karena pengaruh lingkungan. Perubahan warna pada bercak darah disebabkan oleh perubahan hemoglobin menjadi methemoglobin yang menyebabkan warna merah tua menjadi merah kecoklatan. Test Teichmann dilakukan untuk memastikan bercak yang diperiksa adalah darah. Penelitian ini bertujuan untuk membuktikan potensi tes Teichmann untuk mengidentifikasi bercak darah pada pakaian dengan paparan air tawar, tanah, dan udara dengan lama paparan 20 menit, 1×24 jam, $2 \times 24$ jam, 3×24 jam, 4×24 jam, dan 5x24 jam setelah paparan. Dari media dengan paparan air tawar, tanah, dan udara pada 20 menit, 1X24 jam, 2X24 jam, 3X24 jam, 4X24 jam, dan 5X24 jam, didapatkan kristal hematin yang berbentuk batang berwarna gelap kecoklatan yang mengindikasikan hasil positif bercak darah. Kesimpulan dari penelitian ini adalah tes Teichmann dapat mengidentifikasi bercak darah pada pakaian yang dipapar air tawar, tanah, dan udara dalam waktu 20 menit, 1X24 jam, 2X24 jam, 3X24 jam, 4X24 jam, dan 5x24 jam.
\end{abstract}

Kata kunci: Bercak darah, Kristal hematin, Tes Teichmann.

\section{Teichmann Test Application to Identify Bloodstain on Clothes that Exposed to Fresh Water, Soil, and Air}

\section{ABSTRACT}

Blood is one of the most frequent physical evidence found at the crime scene. Blood can discover easily because of its color that dark red, but it can change as it is influenced by the surrounding environment. Color changes in bloodstain could happen due to the transformation of hemoglobin into methemoglobin which changes the bloodstain from dark red to red brown. Teichmann test is conducted to assure whether it is blood or not. This study, was aimed to use Teichmann test to confirm bloodstain on clothes after exposure to fresh water, soil, and air in 20 minutes, $1 \times 24$ hours, $2 \times 24$ hours, $3 \times 24,4 \times 24,5 \times 24$. The result showed that from the medium exposed to fresh water, soil, and air in 20 minutes, $1 \times 24$ hours, $2 \times 24$ hours, $3 \times 24$ hours, 4 X $24, t 5 \times 24$ hours, were found a hematin crystals of dark brown and rod-shaped crystals that suggest it was a bloodstain. The conclusion of this study is Teichmann test can identify bloodstain on clothes that exposed to fresh water, soil, and air in 20 minutes, $1 \times 24$ hours, $2 \times 24$ hours, 3x24, $4 \times 24$ hours, and $5 \times 24$ hours.

Keywords: Bloodstain, Hematin crystals, Teichmann test

* Program Studi Pendidikan Dokter, FKUB

** Laboratorium IImu Kedokteran Forensik, RSSA-FKUB

*** Laboratorium Anatomi Histologi, FKUB 


\section{PENDAHULUAN}

Kriminalitas kerap terjadi di indonesia ini. Ada beberapa faktor yang mempengaruhi kriminalitas di indonesia, di antaranya kemiskinan, disfungsi norma dan hukum, ketidakharmonisan unsur terkait serta karakter bangsa yang sudah bergeser. ${ }^{1}$ Ada beberapa contoh tindak kriminal menurut pidana yaitu pembunuhan, tindak kekerasan, pemerkosaan, pencurian, perampokan, perampasan, penipuan, penganiayaan, penyalahgunaan zat dan obat, dan banyak lagi. ${ }^{2}$ Pembunuhan adalah tindakan yang menghilangkan nyawa orang lain, baik yang dilakukan secara sengaja, direncanakan, maupun secara tidak sengaja. ${ }^{3}$ Kasus pembunuhan di Indonesia yang telah dilaporkan terjadi sebanyak 1.665 kasus pada tahun 2005, 2.524 kasus pada tahun 2006, 1.370 kasus pada tahun 2007, 1.088 kasus pada tahun 2008, dan 1287 kasus pada tahun 2009. ${ }^{4}$

Data di atas menunjukan banyaknya kasus pembunuhan yang terjadi di Indonesia secara keseluruhan. Dalam kasus pembunuhan sering didapatkan bukti-bukti yang terkait dengan pelaku tindak kejahatan baik yang tertinggal di tempat kejadian perkara atau yang melekat pada tubuh si pelaku tindak kejahatan. Bukti fisik dari materi tubuh bisa berupa darah, sperma, rambut, jaringan, urin, feses, dan muntahan. Darah adalah salah satu bukti fisik yang paling sering ditemukan di tempat kejadian perkara. Tak jarang pula darah tersebut melekat pada pakaian pelaku.

Dalam melakukan tindak kejahatan, pelaku pembunuhan biasanya akan membuang barang bukti, seperti dibuang ke suatu tempat yang terpencil, menguburnya dalam tanah, atau membuangnya ke sungai. Tindakan ini dapat menkontaminasi bukti darah yang ada di pakaian pelaku sehingga terjadi perubahan warna. Test Teichmann adalah tes yang dapat dilakukan untuk memastikan apakah yang diperiksa itu adalah bercak darah atau bukan. ${ }^{5}$

Penelitian ini bertujuan untuk mengetahui potensi tes Teichmann dalam mengidentifikasi bukti bercak darah pada pakaian yang terpapar air tawar, tanah, dan udara selama 20 menit, 1X24 jam, 2X24 jam, $3 \times 24$ jam, 4X24 jam, dan 5X24 jam.

\section{BAHAN DAN METODE}

\section{Desain Penelitian}

Penelitian ini adalah studi eksperimental yang dilakukan di laboratorium dengan cara randomisasi.

\section{Populasi}

Penilitian ini tidak memiliki populasi.

\section{Sampel}

Sampel dari penelitian ini adalah pakaian dengan bercak darah. Besar sampel yang digunakan dalam penelitian ini adalah 54 kain dengan bercak darah yang terbagi dalam 6 kelompok berdasarkan waktu paparan yaitu 0 hari (dua puluh menit), $1 \times 24$ jam, 2×24 jam, 3×24 jam, 4×24 jam, dan $5 \times 24$ jam. Masing-masing kelompok terdiri dari 3 helai kain pengamatan. Kain katun dipotong berbentuk persegi dengan panjang sisi $10 \times 10 \mathrm{~cm}$, kemudian kain tersebut ditetesi oleh darah dari satu individu.

\section{Variabel}

Ada 3 variabel yang diamati yaitu variabel bebas berupa darah yang menempel pada pakaian, media pembuangan air tawar, tanah, dan udara, serta lama paparan. Variabel kontrol yaitu pakaian tanpa bercak darah. Variabel terikat yaitu kristal berwarna coklat dengan bentuk batang.

\section{Tempat dan Waktu Penelitian}

Penelitian ini dilakukan di Instalasi Kedokteran Forensik dan Jenazah Rumah 
Sakit dr. Saiful Anwar, Malang pada 10 - 17 Maret 2014.

\section{Analisis Data}

Data hasil tes Teichmann yang diperoleh dari melihat pembuangan pakaian dengan bercak darah dengan media pembuangan dan lama paparan adalah skor - / + atau 0 / 1. Data dianalisis secara deskriptif.

\section{Definisi Operasional}

Definisi operasional dari penilitian ini adalah: (1) Lama paparan sampel dengan media pembuangan air tawar, tanah, dan udara yaitu selama 20 menit, $1 \times 24$ jam, $2 \times 24$ jam, 3×24 jam, 4x24 jam, dan 5x24 jam. (2) Gambaran hasil tes Teichmann yang menunjukkan ada atau tidaknya kristal yang terbentuk. Kristal dengan bentuk batang dan berwarna coklat kehitaman. (3) Satuan positif atau negatif (+/-). (4) Media pembuangan yaitu air tawar dari sumber air sungai dan diletakkan pada wadah berupa ember Tanah yaitu dilakukan dengan kedalaman $20 \mathrm{~cm}$ dengan satu sampel dalam satu lubang. Udara yaitu dengan membiarkan sampel pada udara. . (5) Sampel dibuat dengan menggunakan kain katun yang dipotong berbentuk persegi dengan panjang sisi $10 \times 10 \mathrm{~cm}$, kemudian kain tersebut di tetesi oleh darah dari satu individu.

\section{HASIL}

Melalui pengamatan mikroskop perbesaran $1000 \mathrm{x}$, terlihat gambaran kristal hemin yang merupakan hasil reaksi tes Teichmann. Kristal hemin merupakan kristal berbentuk batang dan berwarna coklat kehitaman.

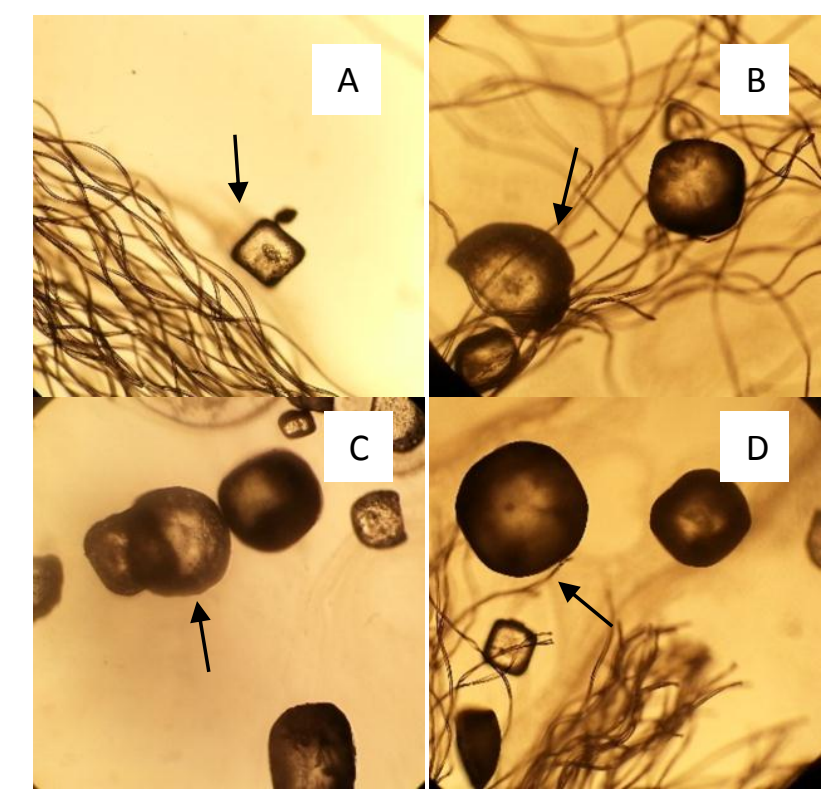

Gambar 1. Kristal hematin (tanda panah) yang teridentifikasi dari media pembuangan air tawar (B), tanah $(C)$, dan udara (D) dengan lama paparan $5 \times 24$ jam yang dibandingkan dengan kontrol $(A)$ (perbesaran 1000x). 
Pada penelitian ini didapatkan hasil pemeriksaan tes Teichman dari 54 buah sampel berupa kristal hematin yang dilihat di bawah mikroskop. Berikut ini merupakan data hasil pemeriksaan tes Teichman.

Tabel 1. Hasil pemeriksaan tes Teichmann pada sampel yang terpapar air tawar, tanah, dan udara selama 20 menit hingga $5 \times 24$ jam.

\begin{tabular}{|c|c|c|c|}
\hline Sampel & Percobaan I & Percobaan II & Percobaan III \\
\hline Air Tawar 20 menit & + & + & + \\
\hline Air Tawar 1x24 Jam & + & + & + \\
\hline Air Tawar 2x24 Jam & + & + & + \\
\hline Air Tawar 3x24 Jam & + & + & + \\
\hline Air Tawar 4x24 Jam & - & + & - \\
\hline Air Tawar 5x24 Jam & + & + & - \\
\hline Tanah 20 menit & + & + & + \\
\hline Tanah 1x24 Jam & + & + & + \\
\hline Tanah 2x24 Jam & + & + & + \\
\hline Tanah 3x24 Jam & + & - & + \\
\hline Tanah 4x24 Jam & - & + & + \\
\hline Tanah 5x24 Jam & + & + & - \\
\hline Udara 20 menit & + & + & + \\
\hline Udara 1x24 Jam & + & + & + \\
\hline Udara 2x24 Jam & + & + & + \\
\hline Udara 3x24 Jam & + & + & + \\
\hline Udara 4x24 Jam & + & + & + \\
\hline Udara 5x24 Jam & + & + & + \\
\hline
\end{tabular}

Berdasarkan Tabel 1 diketahui bahwa pada 20 menit setelah paparan air tawar didapatkan tiga hasil positif. Pada $1 \times 24$ jam setelah paparan, didapatkan tiga hasil positif. Pada $2 \times 24$ jam setelah paparan, didapatkan tiga hasil positif. Pada $3 \times 24$ jam setelah paparan, didapatkan tiga hasil positif. Pada 4X24 jam setelah paparan, didapatkan hasil satu positif dan dua negatif. Pada 5x24 jam setelah paparan, didapatkan hasil dua positif dan satu negatif.

Pada media tanah diketahui 20 menit setelah paparan, didapatkan tiga hasil positif. Pada 1×24 jam setelah paparan, didapatkan tiga hasil positif. Pada $2 \times 24$ jam didapatkan tiga hasil positif. Pada $3 \times 24$ jam setelah paparan, didapatkan hasil dua positif dan satu negatif. Pada 4x24 jam setelah paparan, didapatkan dua hasil positif dan satu hasil negatif. Pada 5x24 jam setelah paparan, didapatkan hasil dua positif dan satu negatif. Dari media paparan udara, pada 20 menit setelah paparan, dari tiga kali percobaan didapatkan tiga hasil positif. Pada 1x24 jam setelah paparan, didapatkan tiga hasil positif. Pada $2 \times 24$ jam setelah paparan, didapatkan tiga hasil positif. Pada $3 \times 24$ jam setelah paparan, didapatkan tiga hasil positif. Pada $4 \times 24$ jam setelah paparan, didapatkan tiga hasil positif. Pada 5x24 jam setelah paparan, didapatkan tiga hasil positif.

Pada percobaan I dengan media paparan air tawar, kemampuan menemukan kristal pada 20 menit setelah paparan dapat dilakukan setelah melakukan tes Teichmann sebanyak dua kali. Pada percobaan II sebanyak dua kali, dan pada percobaan III sebanyak dua kali. Pada percobaan I dengan media paparan air tawar, setelah 1×24 jam, kemampuan untuk menemukan kristal setelah melakukan tes Teichmann sebanyak dua kali. Pada percobaan II sebanyak dua kali, dan pada percobaan III sebanyak dua kali. Pada percobaan I dengan media paparan air tawar, kemampuan menemukan kristal pada $2 \times 24$ jam setelah paparan dapat dilakukan setelah 
melakukan tes Teichmann sebanyak dua kali. Pada percobaan II sebanyak dua kali, dan pada percobaan III sebanyak empat kali. Setelah 3×24 jam, kemampuan untuk menemukan kristal dapat dilakukan setelah melakukan tes Teichmann sebanyak empat kali pada kelompok I. Pada kelompok II sebanyak empat kali, dan pada kelompok III sebanyak empat kali. Setelah 4x24 jam, kemampuan untuk menemukan kristal dapat dilakukan setelah melakukan tes Teichmann sebanyak sebelas kali pada kelompok I. Pada kelompok II sebanyak lima kali. Dan pada kelompok III sebanyak 10 kali. Setelah 5x24 jam, kemampuan untuk menemukan kristal dapat dilakukann setelah melakukan tes Teichmann sebanyak enam kali. Pada kelompok II sebanyak lima kali dan pada kelompok III sebanyak sepuluh kali.

Pada percobaan I dengan media paparan tanah, kemampuan menemukan kristal pada 20 menit setelah paparan dapat dilakukan setelah melakukan tes Teichmann sebanyak dua kali. Pada percobaan II sebanyak tiga kali, dan pada percobaan III sebanyak tiga kali. Pada percobaan I setelah 1x24 jam, kemampuan untuk menemukan kristal setelah melakukan tes Teichmann sebanyak tiga kali. Pada percobaan II sebanyak dua kali, dan pada percobaan III sebanyak tiga kali. Pada percobaan I kemampuan menemukan kristal pada $2 \times 24$ jam setelah paparan dapat dilakukan setelah melakukan tes Teichmann sebanyak tiga kali. Pada percobaan II sebanyak empat kali, dan pada percobaan III sebanyak tiga kali. Setelah 3×24 jam, kemampuan untuk menemukan kristal dapat dilakukan setelah melakukan tes Teichmann sebanyak lima kali pada kelompok I. Pada kelompok II sebanyak sepuluh kali, dan pada kelompok III sebanyak empat kali. Setelah 4x24 jam, kemampuan untuk menemukan kristal dapat dilakukan setelah melakukan tes Teichmann sebanyak sepuluh kali pada kelompok I. Pada kelompok II sebanyak enam kali. Dan pada kelompok III sebanyak enam kali. Setelah 5x24 jam, kemampuan untuk menemukan kristal dapat dilakukann setelah melakukan tes Teichmann sebanyak enam kali. Pada kelompok II sebanyak tujuh kali dan pada kelompok III sebanyak sepuluh kali.

Pada percobaan I dengan media paparan udara, kemampuan menemukan kristal pada 20 menit setelah paparan dapat dilakukan setelah melakukan tes Teichmann sebanyak dua kali. Pada percobaan II sebanyak dua kali, dan pada percobaan III sebanyak dua kali. Pada percobaan I setelah 1x24 jam, kemampuan untuk menemukan kristal setelah melakukan tes Teichmann sebanyak dua kali. Pada percobaan II sebanyak dua kali, dan pada percobaan III sebanyak dua kali. Pada percobaan I kemampuan menemukan kristal pada $2 \times 24$ jam setelah paparan dapat dilakukan setelah melakukan tes Teichmann sebanyak dua kali. Pada percobaan II sebanyak dua kali, dan pada percobaan III sebanyak dua kali. Setelah 3×24 jam, kemampuan untuk menemukan kristal dapat dilakukan setelah melakukan tes Teichmann sebanyak dua kali pada kelompok I. Pada kelompok II sebanyak tiga kali, dan pada kelompok III sebanyak dua kali. Setelah 4×24 jam, kemampuan untuk menemukan kristal dapat dilakukan setelah melakukan tes Teichmann sebanyak tiga kali pada kelompok I. Pada kelompok II sebanyak tiga kali. Dan pada kelompok III sebanyak tiga kali. Setelah $5 \times 24$ jam, kemampuan untuk menemukan kristal dapat dilakukann setelah melakukan tes Teichmann sebanyak tiga kali. Pada kelompok II sebanyak tiga kali dan pada kelompok III sebanyak tiga kali.

\section{PEMBAHASAN}

Darah adalah salah satu dari bukti fisik yang paling sering ditemukan pada tempat kejadian perkara. Hal itu karena darah 
sangat mudah tercecer. Penyelidikan terhadap bercak darah akan sangat berguna untuk mengungkap tindakan kriminal. Bercak darah yang sudah mengering mempunyai penampilan bermacam-macam, seperti abuabu, biru, atau kehijauan. Adapula beberapa yang menyerupai benda-benda lain seperti karat yang tercampur dengan air atau cat. ${ }^{5}$ Hal yang berperan dalam perubahan warna pada bercak darah adalah perubahan hemoglobin menjadi methemoglobin yang menyebabkan warna darah yang awalnya adalah merah tua menjadi merah kecoklatan. Hal ini menyebabkan bercak darah tersebut menjadi sulit dibedakan dengan bercak noda lain yang berwarna kecoklatan.

Berdasarkan hasil di atas diketahui bahwa dari media paparan air tawar didapatkan kristal hematin utuh yang berarti tes Teichmann dapat mengidentifikasi bercak darah dengan paparan air tawar setelah 20 menit. Pada 1×24 jam setelah paparan air tawar, didapatkan kristal hematin utuh yang berarti tes Teichmann dapat mengidentifikasi bercak darah. Pada $2 \times 24$ jam dan 3×24 jam setelah paparan air tawar, didapatkan kristal hematin utuh yang berarti tes Teichmann dapat mengidentifikasi bercak darah. Pada 4×24 jam setelah paparan air tawar, didapatkan kristal hematin yang tidak utuh yang berarti tes Teichmann tidak dapat mengidentifikasi bercak darah. Pada $5 \times 24$ jam setelah paparan air tawar, didapatkan kristal hematin yang utuh yang berarti tes Teichmann dapat mengidentifikasi bercak darah walaupun ditemukan 1 kelompok yang menunjukkan bentukan kristal yang tidak utuh.

Berdasarkan hasil tes Teichmann pada media paparan tanah didapatkan kristal hematin utuh yang berarti tes Teichmann dapat mengidentifikasi bercak darah dengan paparan tanah setelah 20 menit. Pada 1x24 jam setelah paparan tanah, didapatkan kristal hematin utuh yang berarti tes
Teichmann dapat mengidentifikasi bercak darah. Pada 2x24 jam setelah paparan tanah, didapatkan kristal hematin utuh yang berarti tes Teichmann dapat mengidentifikasi bercak darah. Pada 3×24 jam, 4×24 jam, dan $5 \times 24$ jam setelah paparan tanah, didapatkan kristal hematin utuh yang berarti tes Teichmann dapat mengidentifikasi bercak darah. walaupun ditemukan 1 kelompok yang menunjukkan bentukan Kristal yang tidak utuh.

Berdasarkan hasil tes Teichmann pada media paparan udara didapatkan kristal hematin utuh yang berarti tes Teichmann dapat mengidentifikasi bercak darah dengan paparan udara setelah 20 menit. Pada 1x24 jam setelah paparan udara, didapatkan kristal hematin utuh yang berarti tes Teichmann dapat mengidentifikasi bercak

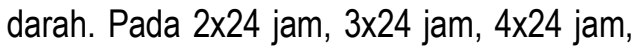
dan $5 \times 24$ jam setelah paparan udara, didapatkan kristal hematin utuh yang berarti tes Teichmann dapat mengidentifikasi bercak darah.

Selain itu, dari masing-masing media paparan terbukti menghasilkan kristal hematin yang berbeda-beda, dengan paparan air tawar dan tanah lebih sulit dibandingkan pada paparan udara. Bercak darah dengan paparan udara akan mengering dan zat besi dalam heme dapat bertahan untuk waktu yang tidak terbatas tergantung pada tingkat paparannya. ${ }^{6}$ Bercak darah dengan paparan air tawar dan tanah memiliki lingkungan yang hangat dan lembab dan adanya bakteri dan mikroorganisme lainnya bisa mempengaruhi bercak darah tersebut. ${ }^{7}$

\section{KESIMPULAN}

Penelitian ini menyimpulkan bahwa tes Teichmann dapat mengidentifikasi bercak darah pada pakaian dengan paparan tanah, air tawar, dan udara bebas dengan lama 
paparan 20 menit, $1 \times 24$ jam, $2 \times 24$ jam, 3×24 jam, 4x24 jam, dan 5x24 jam.

\section{DAFTAR PUSTAKA}

1. Piter R. Indonesia dalam Bigkai Kriminalitas. (Online). 2012. http://hankam.kompasiana.com/2012/01 104/indonesia-dalam-bingkai-

kriminalitas.

2. Margaretha. Mengapa Orang Melakukan Kejahatan?. (Online). 2012. http://margarethafpsi.web.unair.ac.id/arti kel-detail-61501-kejahatan mengapa $\% 20$ orang $\% 20$ melakukan $\% 20$ kejahatan.html.

3. Supriatna N, Ruhimat M, dan Kosim,. IPS Terpadu. (Online) books.google.com/books?isbn= 9797583 $\underline{384}$

4. Pusat Informasi Kriminal Nasional. (Online). 2010. http://ncic.polri.go.id/.

5. Layle DP. Howdunit Forensics. (Online). 2008. http://books.google.com/books?isbn=15 82974748

6. Paonessa N. Bloodstains of Gettysburg: The Use of Chemiluminescent Blood Reagent ro Visualize Bloodstains of Historical Significance. Case Report. New York: IABPA. 2008.

7. James SH, Kish PE, and Sutton TP. Principle of Bloodstain Pattern Analysis Theory and Practice. Danvers: CRC press. 2005. 